\title{
Thermal Comfort Disturbed by Local Airflows in Winter
}

\author{
Listiani Nurul Huda*1, Hiroshi Homma ${ }^{2}$, Nahomi Matsubara ${ }^{1}$ and Chanhngakham Phonesavanh ${ }^{1}$
}

\author{
${ }^{1}$ Graduate Students, Department of Architecture and Civil Engineering, Toyohashi University of Technology, Toyohashi, Japan \\ ${ }^{2}$ Professor Department of Architecture and Civil Engineering, Toyohashi University of Technology, Toyohashi, Japan
}

\begin{abstract}
The human body is enveloped in a natural convection that is created by the body's own metabolic heat. This natural convection does not cover the body's surface equally, however, so disturbances caused by outside airflows are also not equal over the body surface. In this study, horizontal local airflows of various temperatures and velocities were directed at two locations on the bodies of several subjects: the backs of the necks and the left sides of the ankles. In this paper, the subjects' perceptions of temperature and air motion at both locations were compared during experiments held in winter. Airflows directed at the ankles were perceived to be higher in temperature and velocity than identical airflows directed at the back of the necks, while airflows directed at the neck produced greater thermal comfort than identical airflows directed at the ankles. Therefore, the percentage of dissatisfied (PD) was smaller at the neck than at the ankles. In practical terms, to prevent the sensation of being cold, low-temperature airflows directed at the ankles should be avoided, and to increase comfort at the neck, high-temperature, high-velocity airflows should be avoided.
\end{abstract}

Keywords: back of neck; ankle; local airflow; sensation; thermal comfort

\section{Introduction}

People living in hot and humid climates enjoy a good breeze, but the same breeze will cause discomfort to those living in cool and mild climates. Although air movements are needed even in cool climates to increase comfort and freshen the air in enclosed living spaces, these air movements can produce unwanted cooling effects. Rather than directing the airflow against the whole body, it is more practical to send air to a specific location on the body that is sensitive to the temperature and velocity of the airflow but will not be disturbed by it. To find such a location, the mechanism of sensation caused by local airflows should be divided into two stages. The first stage is physical stimulation of a body's surface by the airflow. A local airflow may cause local differences in the stimulation of a body surface because it travels through a natural convection boundary layer. The second stage includes physiological perception of the airflow at the surface and the generation of sensation from the perception.

Various research results have been published on local sensation. Houghten et al. (1938), and Fanger and Christensen (1986) suggested that the backs of the necks were less tolerant of cold drafts than the ankles. On the other hand, the importance of the temperature in the lower part of a room was suggested by Wyon et al. (1969),

*Contact Author: Listiani Nurul Huda, Graduate Student, Department of Architecture and Civil Engineering, Toyohashi University of Technology, Toyohashi Japan, 441-8580

Tel: +81-532-44-0111 (ext. 5607); Fax: +81-532-44-6831

e-mail: nurul@einstein.tutrp.tut.ac.jp

(Received November 8, 2003 ; accepted April 6, 2004) and Gonzales and Nishi (1976).

The conditions of thermal comfort differ for the back of the neck and the ankles. Homma (1988) suggested that the human body is enveloped by rising airstreams, and the velocity corresponds to the highest acceptable air velocity for comfort. Toftum, Zhou, and Melikov (1997) showed that at $20^{\circ} \mathrm{C}$ and $23^{\circ} \mathrm{C}$, an airflow from below was perceived as being the most uncomfortable followed by airflows towards the back and front. At $26^{\circ} \mathrm{C}$, the airflow from above and towards the back caused the most dissatisfaction due to the draught, but generally only a few of the subjects perceived discomfort at this temperature. Homma (2001) studied the physical side of the thermal comfort of a local draft. A thermal manikin was used to compare the effects of the draft at the back of the neck and at the ankle. The results indicate that local airflows affect the ankles more strongly than the necks.

In the present study, local airflows with a range of velocities wider than that defined by ASHRAE and ISO standards as allowable velocities were directed at the back of the neck and at the ankles of the test subjects. These locations were chosen because the natural convection of body heat starts at the ankle level and fully develops at the neck level. The differences in the subjects' perceptions of temperature and airflow, and their feelings of comfort were examined. If a draft is felt more strongly at either of these locations, it is effective to limit the draft only at this location. This study used human subjects in order to find a range of comfort that reduced discomfort at these locations. In order to distinguish the physiological responses of a human body, the following laboratory experiment was conducted. 
questionnaire. During the next 75 minutes, the subjects were exposed to local airflows having one of the above four conditions. Five consecutive 15-minute periods consisted of stepped changes in either temperature or velocity. Three times during each 15 -minute period, the subjects noted their responses on the questionnaire. (See also Figure 1.) After the experiment, the responses were converted into numbers for statistical evaluation. The questionnaire is shown in Figure 3.
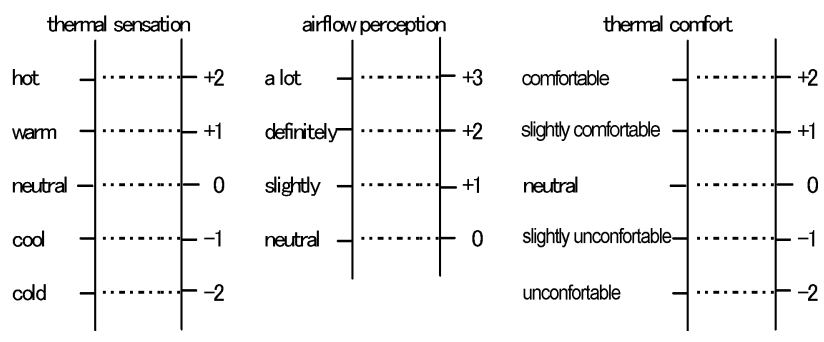

Fig.3. Design of the Questionnaire

\section{Results}

The means and standard deviations of the subject's votes regarding thermal sensation, airflow perception, and thermal comfort were calculated using the SPSSStatistical Package. The results are shown in Table 2. The ANOVA test, which had a confidence interval of $95 \%$, shows the votes to the three questions for the four experimental conditions. The votes were significantly different for the necks and the ankles and had a covariance coefficient (F) larger than 4 , as shown in Table 3.

Table 4 shows a statistical analysis of the votes by gender to the three questions in the questionnaire. The gray colored portions indicate statistical results that were not significantly different.

The ages, heights, and weights of the subjects had no significant influence on the responses for the three questions.

\subsection{Thermal Sensation}

The mean votes by males and females to thermal

Table 3. ANOVA results for tuvc, tdvc, tcvu, tcvd

\begin{tabular}{|l|l|c|c|c|}
\hline Location & \multicolumn{1}{|c|}{ Votes } & $\mathrm{N}$ & $\mathrm{F}$ & $\mathrm{p}<$ \\
\hline \multirow{3}{*}{ Neck } & Thermal sensation & 3600 & 6.649 & 0.05 \\
& Airflow perception & 3600 & 15.930 & 0.005 \\
& Thermal comfort & 3600 & 6.018 & 0.05 \\
& & & & \\
\multirow{3}{*}{ Ankle } & Thermal sensation & 3600 & 4.045 & 0.05 \\
& Airflow perception & 3600 & 11.940 & 0.005 \\
& Thermal comfort & 3600 & 5.221 & 0.05 \\
\hline
\end{tabular}

sensation in all four experimental conditions ranged from -0.829 to 0.744 for the necks and from -1.110 to 0.618 for the ankles.

Figure 4 (a) shows the results of the temperaturechange experiments. All of the lines for thermal sensation at the necks and the ankles increased with temperature. The gradients of the regression lines were lower at the ankles than at the necks. For the airflow with a temperature difference of $-10^{\circ} \mathrm{C}$, the thermal sensations at the neck and ankles were slightly cool. The thermal sensation increased gradually as the temperature rose, and approached neutral sensation at an airflow temperature difference of $+10^{\circ} \mathrm{C}$. Most of the votes indicated cooler sensations at the ankles than at the necks.

The gradients of the regression lines had different trends in the two velocity-change experiment, as shown in Figure 4 (b). In the velocity increase experimental condition (tcvu), the regression lines were steeply negative at both body locations. The values for the ankles were less than those for the necks. When the air velocity was $0 \mathrm{~m} / \mathrm{s}$, the average votes at the necks and ankles ranged around a slightly warm sensation, and shifted to a range around a slightly cool sensation when the air velocity was $1.00 \mathrm{~m} / \mathrm{s}$. All of the votes at the ankles were lower than those at the neck. In the velocity-decrease experiment (tcvd), the gradient was very gently but still negative at the necks, but was positive at the ankles. When the air velocity was $0 \mathrm{~m} / \mathrm{s}$, the thermal sensation at the neck was almost neutral and slightly decreased as the air velocity increased, while it increased at the ankles. At an air velocity of $1.00 \mathrm{~m} / \mathrm{s}$, the thermal sensation was slightly cool at the necks but slightly warm at the ankles.

The votes for thermal sensation were significant, with a probability (p) of less than 0.005 in all of four experiments and at both body locations. The thermal sensation in the temperature- and the velocity-change experiments differed significantly for the necks and the ankles, with a significance level of 5\% and a $p$ value of less than 0.005 .

Table 4. Comparison of ANOVA results for male and female subjects

\begin{tabular}{|l|l|c|c|c|c|c|}
\cline { 5 - 7 } \multicolumn{2}{c}{} & \multicolumn{1}{c}{ Temperature change } & \multicolumn{2}{c|}{ Velocity change } \\
\hline \multirow{3}{*}{ Location } & \multicolumn{1}{c}{ Votes } & $\mathrm{N}$ & $\mathrm{F}$ & $\mathrm{p}$ & $\mathrm{F}$ & $\mathrm{p}$ \\
\hline \multirow{5}{*}{ Ankle } & Thermal sensation & 1800 & 4.634 & 0.031 & 10.515 & 0.001 \\
& Airflow perception & 1800 & 2.245 & 0.134 & 20.832 & 0.000 \\
& Thermal comfort & 1800 & 4.546 & 0.330 & 0.063 & 0.802 \\
& & & & & & \\
& Thermal sensation & 1800 & 0.637 & 0.425 & 25.845 & 0.000 \\
& Airflow perception & 1800 & 4.176 & 0.410 & 10.536 & 0.001 \\
& Thermal comfort & 1800 & 0.792 & 0.373 & 0.210 & 0.647 \\
\hline
\end{tabular}

Table 2. Mean and Standard Deviations by Experimental Conditions

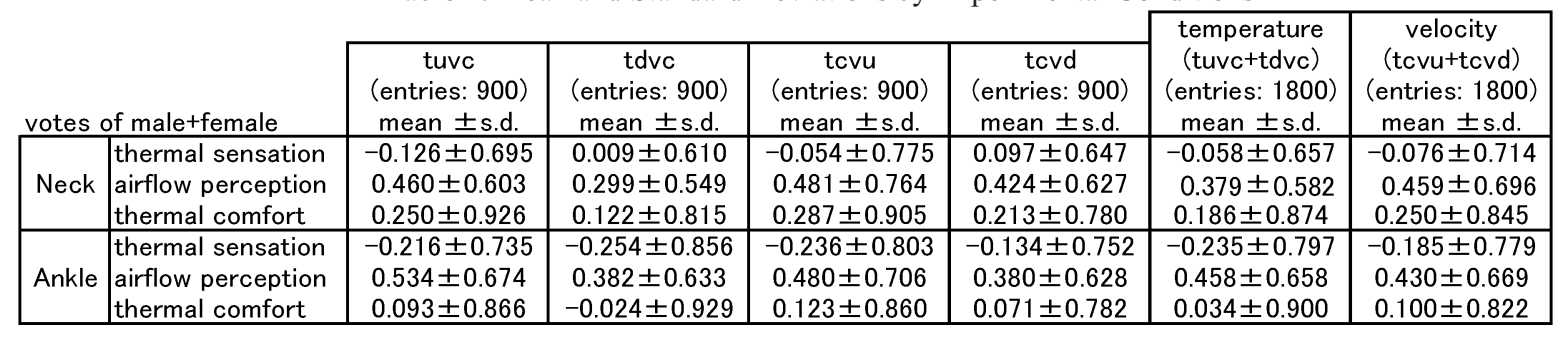






(a) Temperature Change

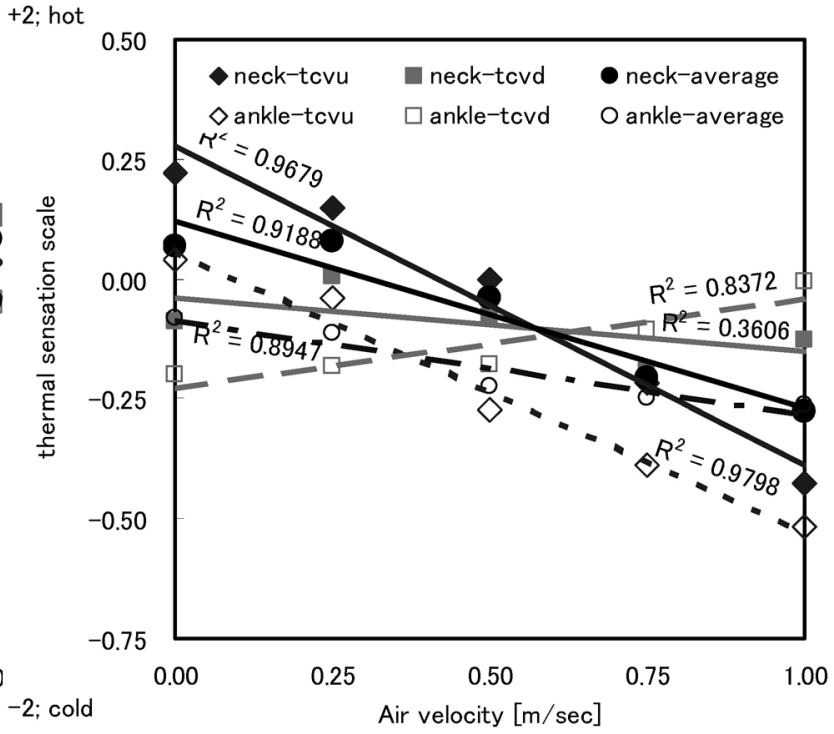

(b) Velocity Change

Fig.4. Thermal Sensation Votes by Temperature and Velocity Change Experiments

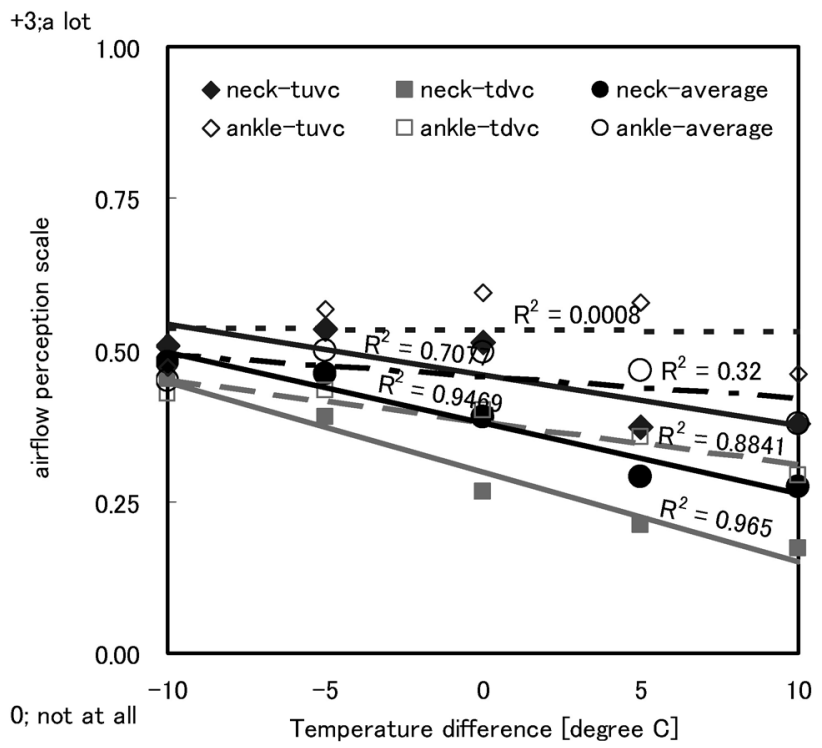

(a) Temperature Change

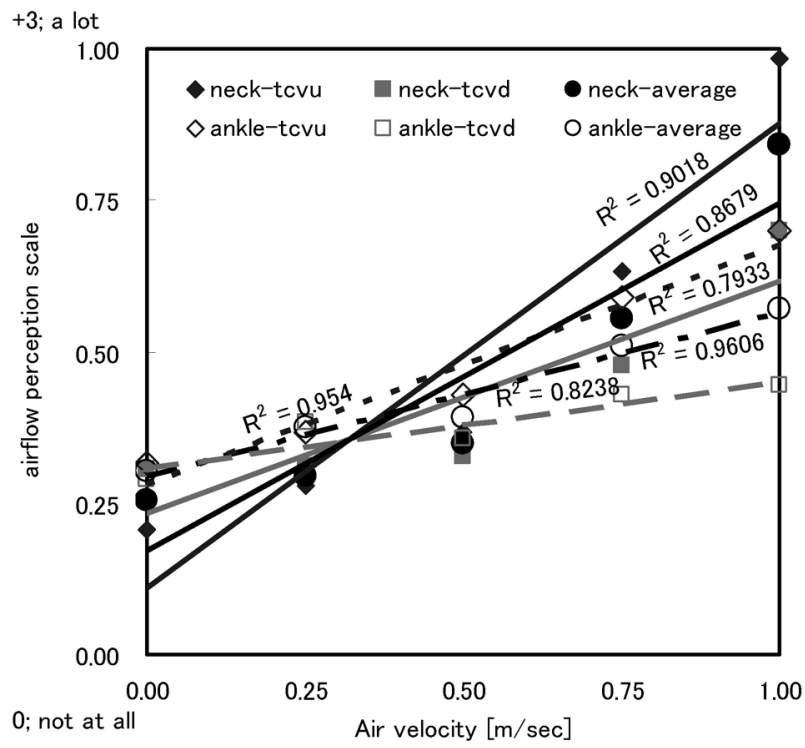

(b) Velocity Change

Fig.5. Airflow Perception Votes by Temperature and Velocity Change Experiments

\subsection{Airflow Perception}

The means for all the votes in the temperature- and velocity-change experiments by males and females ranged from 0.298 to 0.808 at the necks and from 0.555 and 0.713 at the ankles. The regression lines for the temperature- and velocity-change experiments had different gradients, as shown in Figure 5. In the temperature-change experiments, the regression lines were lower at the neck than at the ankles. At the cooler temperatures, the airflow was perceived to be slight at both locations and decreased gradually as the temperature difference increased. The perception of airflow at the ankles was more definite than at the necks. In the velocity-change experiments, all of the regression lines increased as the velocity increased at the necks and the ankles, as shown in Figure 5 (b). At low velocities, the airflow was only very slightly perceived at the both locations but the perception became more definite when the air velocity was at the highest level. At air velocities below $0.25 \mathrm{~m} / \mathrm{s}$, the perception of airflow was lower at the necks than at the ankles. At air velocities above 0.25 $\mathrm{m} / \mathrm{s}$, however, the perception of airflow was higher at the necks than at the ankles.

The votes for airflow perception were significant, with the $p<0.005$ for all four experimental conditions and at both locations. Airflow perceptions at the necks and ankles in the temperature-change experiments differed significantly from those in the velocity-change experiments, with a significance level of $5 \%$ and a $p$ value of less than 0.005 . 


\subsection{Thermal Comfort}

The mean votes by males and females for thermal comfort for all four experimental conditions ranged from -0.693 to 1.192 at the necks and from -0.953 to 0.983 at the ankles. The average thermal comfort response was higher at the necks than at the ankles in all four conditions, as shown in Figure 6.

The mean votes for thermal comfort in the tuvc and tdvc experiments increased slightly as the temperature difference at the necks and the ankles increased, as shown in Figure 6 (a). In the lower temperatures, thermal comfort was higher in the temperature-increase experiment than in the temperature decrease experiment for both locations. Thermal comfort was negative in the lower temperatures at the ankles in the temperaturedecrease experiments. At the higher temperatures, all of the thermal comfort votes approached the neutral condition. In this condition, the ankles felt more comfortable in the temperature-decrease experiments than in the temperature-increase experiments. Figure 6 (b) shows that the mean votes for thermal comfort increased as the velocity increased at the necks and the ankles. In the slower air velocities, thermal comfort was higher in the velocity-increase experiments than in the velocity-decrease experiments for both locations, but at air velocities faster than $0.5 \mathrm{~m} / \mathrm{s}$, thermal comfort was lower. As the thermal comfort votes had complicated relationships with the four conditions of the experiments, the $\mathrm{F}$ values were significant only at the neck in the velocity-change experiments $(\mathrm{p}<0.005)$.

\subsection{Comparison of Sensitivities of Necks and Ankles}

The thermal sensation, velocity perception, and thermal comfort at the two locations in the temperatureand velocity-change experiments are compared in Figure 7. Figure 7 (a) shows many votes below the two diagonal lines, indicating that the airflow was perceived to be



(a) Temperature Change cooler at the ankles than at the necks. In the velocitychange experiments, the perceptions of airflow were stronger at the necks than at the ankles, but this was reversed in the temperature-change experiments, as shown in Figure 7 (b). This means that the neck was more sensitive than the ankles to airflow and that the ankles were more sensitive than the neck to temperature. Figure 7 (c) shows many votes below the line of equal sensation in the first quadrant. This indicates that the airflow was more comfortable at the back of the necks than at the ankles. All of these relationships were significant, with $\mathrm{p}<0.005$.

\subsection{Percentage of Dissatisfied}

The percentages of dissatisfied (PD) were calculated from the comfort votes. When an average response was below -0.5 over the full scale of -2 to 2 , the response was assumed to be one of dissatisfaction. Figure 8 (a) shows that, in the temperature-change experiments, the average PD was about $14 \%$ at the necks, and about $21 \%$ at the ankles. At temperature differences below $-5^{\circ} \mathrm{C}$, female subjects had a higher PD at the necks than did males. But at higher temperature differences, this was reversed. The PD was lowest for both genders at a temperature difference of $0^{\circ} \mathrm{C}$. Above a temperature difference of $-5^{\circ} \mathrm{C}$, the males felt more dissatisfaction at the necks than did females. At the ankles, females had a lower PD than did males when the temperature difference was below $5^{\circ} \mathrm{C}$. For other temperature differences, the PD was higher for females than for males. At the ankles, the PD for both genders appeared to decrease as the temperature difference increased. Both genders had the lowest PD at the highest temperature difference.

The PDs for the velocity-change experiments are shown in Figure 8 (b). In general, the PD appeared to increase as the velocity increased. For both genders, the PD was lower at the necks than at the ankles for air

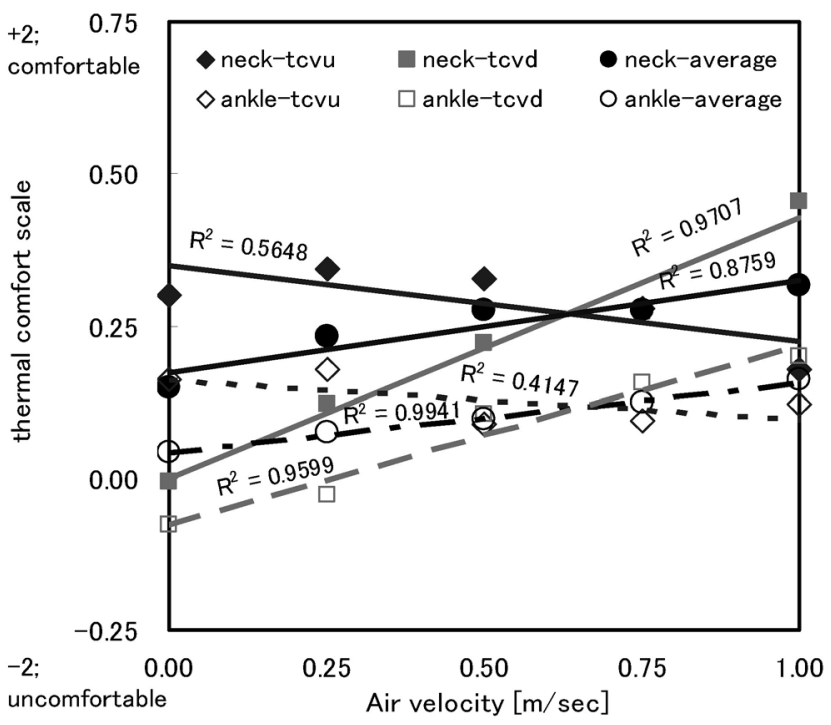

(b) Velocity Change

Fig.6. Thermal Comfort Votes by Temperature and Velocity Change Experiments 


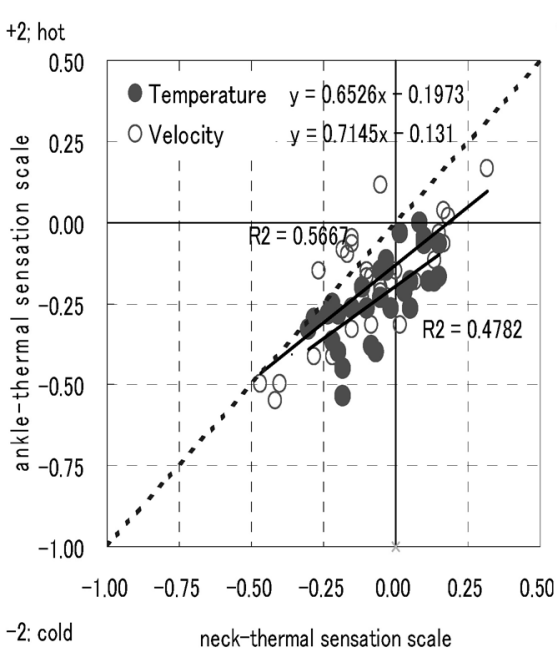

(a) Thermal Sensation

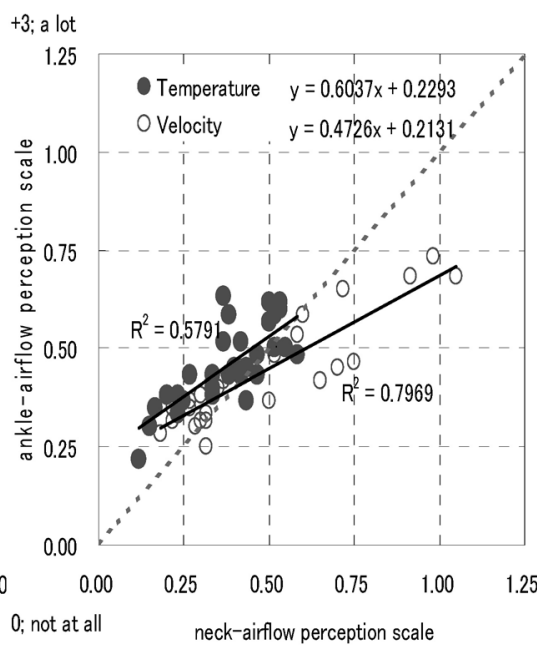

(b) Airflow Perception

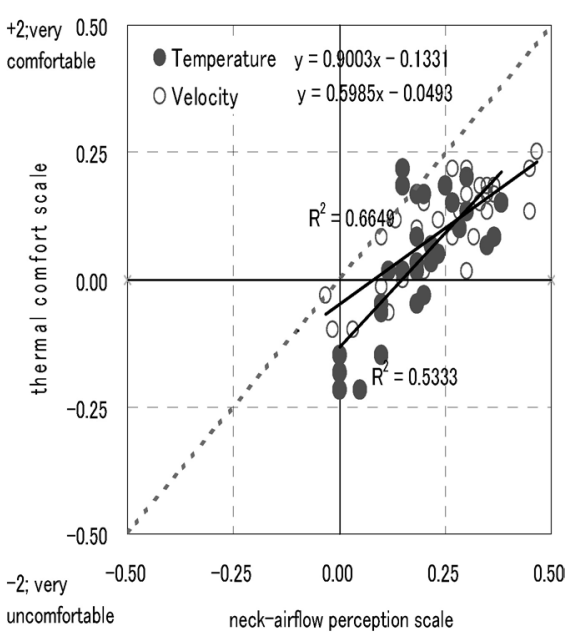

(c) Thermal Comfort

Fig.7. Comparison of Neck and Ankle in the Temperature- and Velocity-change Experiments

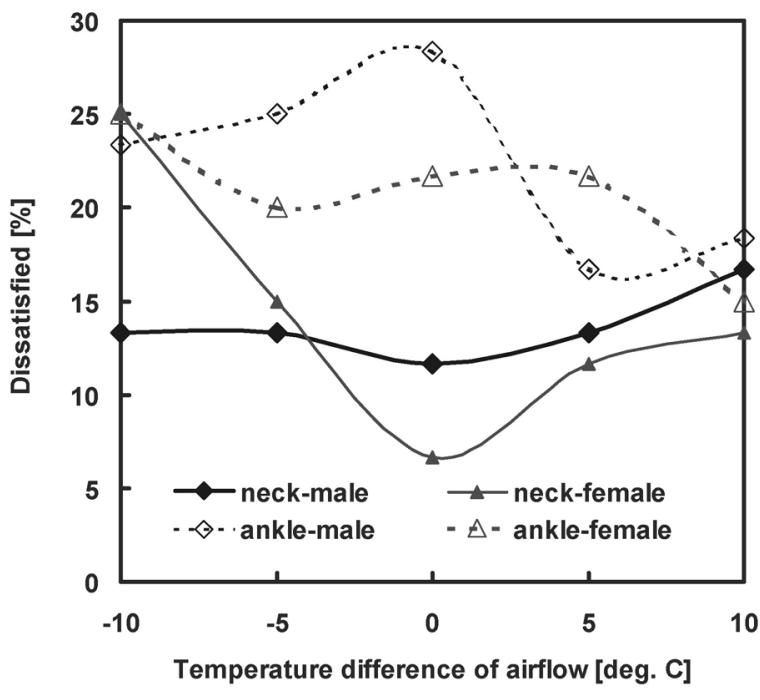

(a) Temperature Change

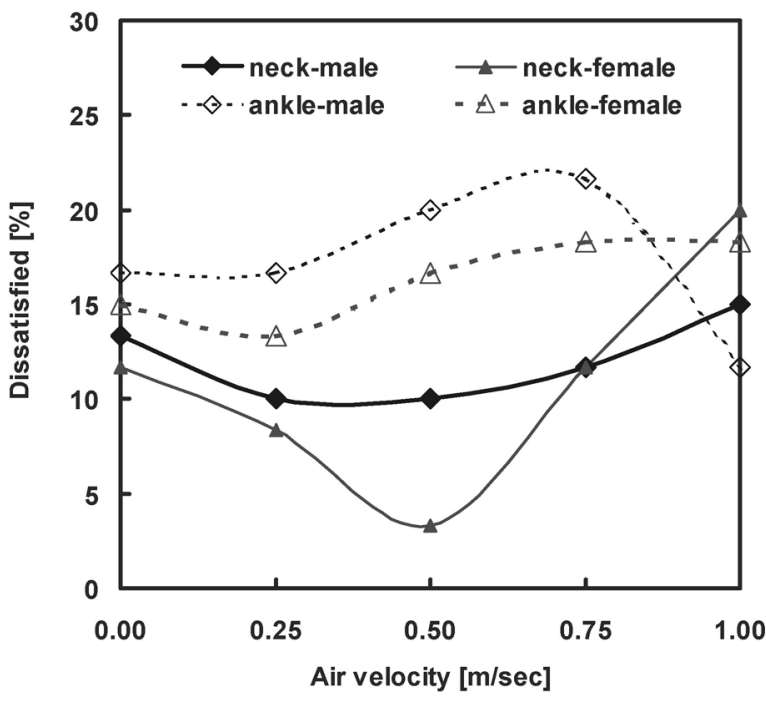

(b) Velocity Change

Fig.8. Percentage of Dissatisfied

velocities below $0.75 \mathrm{~m} / \mathrm{s}$. All of the PDs for females were smaller than those for males in all of the velocitychange experiments.

\section{Discussion}

\subsection{Influence of Temperature and Velocity}

In the discussion above, it was indicated that local airflows with different temperatures or different air velocities produced different sensations of thermal comfort at the back of the neck and at the ankles. But it was found that the local airflow produced different sensations even for common conditions in the four experiments (tuvc, tdvc, tcvu, and tcvd). The frequency distribution of thermal comfort votes tabulated by combining the three votes at the common condition as the mean value. This is shown in table 5. The average of the male and female votes are also plotted in Figure 9, which shows that the frequency of the thermal comfort votes had different patterns in the temperature- and velocity-change experiments even under common neutral conditions, which were a combination of a $0^{\circ} \mathrm{C}$ temperature difference and a $0.5 \mathrm{~m} / \mathrm{s}$ velocity.

Average thermal comfort votes below -0.5 were assumed to be indications of discomfort. Comfort votes between -0.5 and 0.5 were assumed to indicate a neutral condition. Average thermal comfort votes above 0.5 were assumed to be indications of comfort.

Slightly fewer subjects (about 1\% fewer) felt discomfort at the neck in the temperature-change experiments than felt so in the velocity-change 
Table 5. Frequency of thermal comfort votes
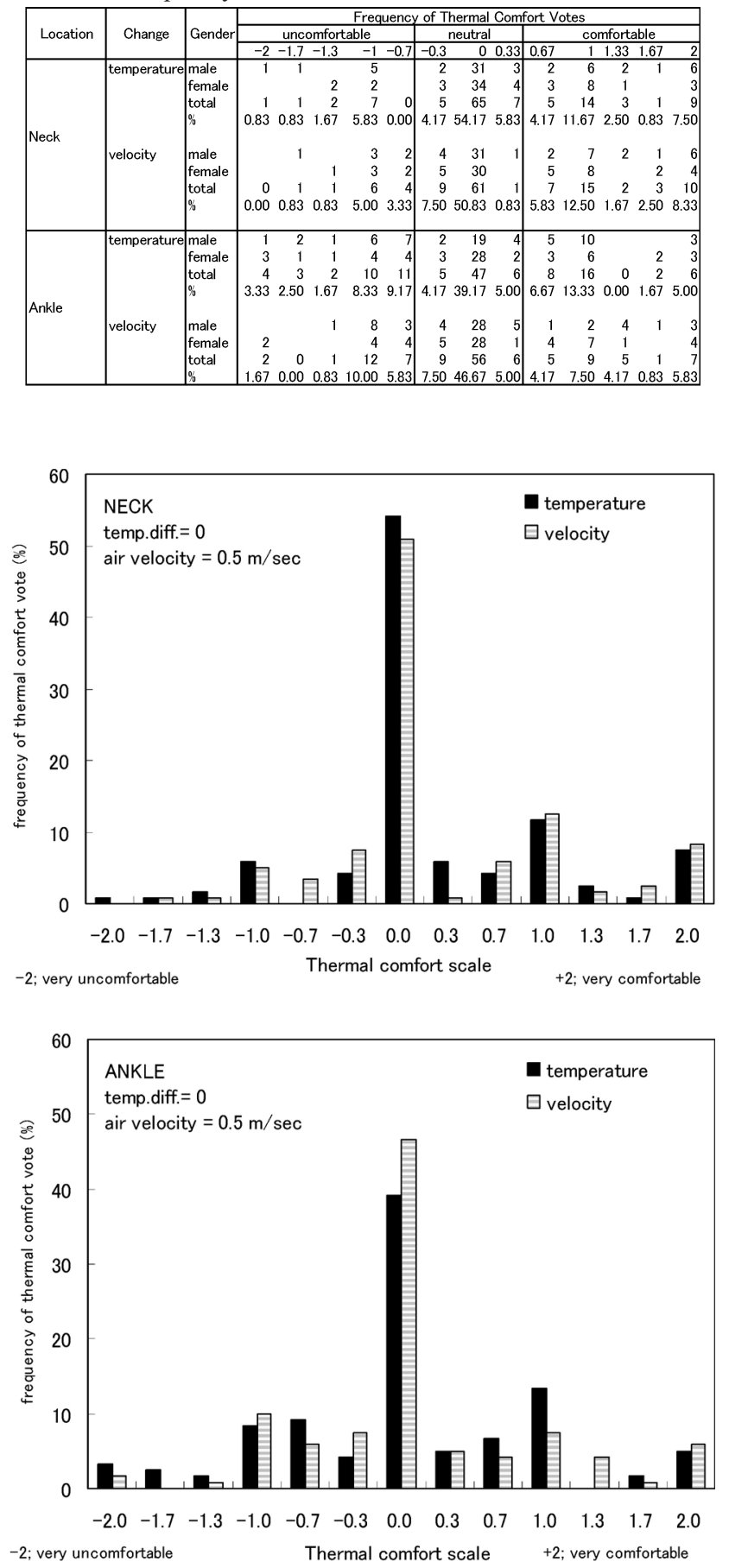

Fig.9. Votes Frequency in Neutral Conditions

experiments; $91 \%$ of those in the temperature-change experiments felt neutral and comfortable while $90 \%$ felt so in the velocity-change experiments. The number of votes for thermal comfort was lower by about $4 \%$ for the temperature-change experiments. A larger number of subjects (about $7 \%$ more) felt discomfort at the ankles in the temperature-change experiments than felt so in the velocity-change experiments; $75 \%$ of subjects felt neutral and comfortable in the temperature-change experiments, while $82 \%$ felt so in the velocity-change experiments. At the necks, the votes during the temperature-change experiments were concentrated in the neutral region, but in the velocity-change experiments, the votes were more evenly distributed. At the ankles, this was reversed.

As defined in ASHRAE Standard 55, an allowable thermal environment is any environment in which $80 \%$ of the occupants accept the conditions. The experiments in this study were conducted under these conditions. The mean air velocity was under $0.18 \mathrm{~m} / \mathrm{s}$, and votes above 0.5 in the 7-step scale were assumed to be indications of comfort. The present results showed that a local airflow with a velocity of $0.5 \mathrm{~m} / \mathrm{s}$ at the two body locations was not disagreeable.

In a study by B. Griefahn et al. (2000) on the significance of air velocity and turbulence intensity for votes to horizontal drafts in a constant air temperature of $23^{\circ} \mathrm{C}$, the mean air velocity was directed toward various dorsolateral sites on the bodies of sedentary persons. The mean velocity varied in 4 steps $\left(\mathrm{v}_{\mathrm{a}}: 0.1\right.$, $0.2,0.3,0.4 \mathrm{~m} / \mathrm{s}$ ) and the turbulence intensity in 3 steps $\left(\mathrm{T}_{\mathrm{u}}:<30,50,>70 \%\right)$. The results showed that draftinduced general annoyance (if draft-induced annoyance was stated for at least one body site) and draft-induced local annoyance as stated for the neck and for the forearm increased as air velocity and/or turbulence intensity increased. The present results of airflow perception at the neck and ankles agree with Griefahn's results even though the air velocity range of the present results is wider than the mean velocity range of Griefahn's results. Concerning rather sedentary persons, it seems that drafts are tolerable so long as the mean air velocity does not exceed $0.2 \mathrm{~m} / \mathrm{s}$ and the turbulence intensity remains below $30 \%$ in an air temperature of $23^{\circ} \mathrm{C}$. In the present study, it was found that, throughout the present velocity range at both body locations, thermal comfort increased as the air velocity increased.

In a study of convective heat transfer in a thermal manikin disturbed by local airflows, Homma (2001) noted that local airflows more strongly stimulated the ankles than the back of the neck. In the present subjective experiments, local airflows were perceived to be cooler at the ankles than at the necks. The airflows were perceived more strongly at the ankles than at the necks in the temperature-change experiments, but this relation was reversed in the velocity-change experiments. Thermal comfort was higher at the necks than at the ankles in both the temperature- and velocity-change experiments. Even if the physical result has meaning, the physiological and psychological sensations appeared to be different in the present experiment.

\subsection{Influence of Temperature and Velocity on Males and Females}

The different perceptions of thermal comfort by males and females were investigated by Rohles and Nevins (1971). They found that males were significantly warmer than females during the first hour of exposure. In the present experiments, the exposure time was 1 hour and 
15 minutes. But it included stepped increases and decreases in temperature or velocity. The average results of the temperature increase and decrease experiments showed that the males felt more comfortable than females in temperature differences of $-10^{\circ} \mathrm{C}$ and $-5^{\circ} \mathrm{C}$ at the necks, but above $-5^{\circ} \mathrm{C}$, the females felt more comfortable. The males felt more uncomfortable than the females at temperature differences below $5^{\circ} \mathrm{C}$ at the ankles, but above $5^{\circ} \mathrm{C}$, the males felt more comfortable. Males felt more uncomfortable at both locations throughout the velocity-change experiments. At the necks in the temperature-change experiments, the thermal comfort range of the males was wider than that of the females, but at the ankles, the thermal comfort range of the males was narrower than that of the females.

\section{Conclusion}

Differences in temperature sensation, airflow perception, and thermal comfort were found at the back of the neck and at the ankles in the temperature-and velocity-change experiments. The ankles were more sensitive than the back of the neck to lower temperatures, while the back of the neck was more sensitive to higher temperatures and velocities. These findings may indicate that low-temperature airflows directed at the ankles should be avoided. Also, to keep the neck comfortable, high-temperature, high-velocity airflows should be avoided. Increases in temperature and velocity, however, do not always reduce thermal comfort at the neck and ankles even in winter. The PD was found to differ between locations and genders. These differences may be caused in part by the body's natural convection and by local differences in the perceptions of temperature and velocity.

\section{Acknowledgments}

This study was supported in part by the $21^{\text {st }}$ Century COE Program on "Ecological Engineering for Homeostatic Human Activities" of the Ministry of Education, Culture, Sports, Science and Technology, Japan.

\section{References}

1) ASHRAE (1992) ANSI/ASHRAE Standard 55-1992. Thermal environmental conditions for human occupancy. Atlanta: American Society of Heating, Refrigerating and Air Conditioning Engineers, Inc., chapter 8

2) B.Griefahn et al. (2000) The significance of air velocity and turbulence intensity for responses to horizontal drafts in a constant air temperature of $23^{\circ} \mathrm{C}$. International Journal of Industrial Ergonomics 26, pp. 639-649.

3) Fanger, P.O, and Christensen, N.K., (1986) Perception of draught in ventilated spaces, Ergonomics 29 (2), pp. 215-235.

4) F.H. Rohles and R.G. Nevins. (1971) The nature of thermal comfort for sedentary man. ASHRAE Research Report , pp.239-246

5) Homma, H. (1988) Examination of free convection around occupant's body caused by its metabolic heat, ASHRAE Transactions 94(1): pp 104-124

6) Homma, H. (2001) An Experimental Study of Convection Heat Transfer of a body disturbed by local airflow. ASHRAE Transactions 2002, Vol. 107, Part 2, pp.406-414

7) Houghten, C.F. et al. (1938) Draft temperatures and velocities in relation to skin temperature and feeling of warmth. Transactions of ASHVE, pp.289-308.

8) J. Toftum et al. (1997) Effect of airflow direction on human perception of draught. Clima 2000, August 1997 Brussels, paper 366

9) K. Cena and J. A. Clark. (1981) Bioengineering, Thermal Physiology and Comfort. Studies in Environmental Science 10. Elsevier Scientific Publishing Company.

10) Richard R.Gonzales and Yosunobu Nishi. (1976) Effect of Cool Environments on Local Thermal Sensation, Discomfort and Clothing Selection. ASHRAE Transaction. Vol. 76 (1), pp 76-86.

11) SPSS-Statistical Package Release 11.0E for Windows.

12) Wyon, D.P. et al. (1969) Thermal Comfort during Surgical Operations, JIHVE Vol. 37, Oct., pp.150-168 